\title{
Reflections of the quality of primary care in Canada and Israel
}

\author{
Richard H. Glazier ${ }^{1,2,3}$ (1)
}

\begin{abstract}
Rachel Podell and her colleagues at the National Program for Quality Indicators in Community Healthcare in Israel have provided a clear and engaging description of thequality of primary care provided to the elderly in Israel. They examine changes overtime, variation across sub-groups, and comparisons with other countries. Over a 13year timeframe, most of the included process measures improved substantially, withfairly minor differences between demographic groups and largely favourablecomparisons with other countries.

In the Podell et al article, there are few direct comparisons of primary care available between Canada and Israel, but we know from other studies that Canadian primary care compares relatively unfavourably with ten other developed countries in a number of measures. These include timely access to care, after-hours care, electronic medical record use and audit and feedback for quality improvement. More concerning is that few of these measures have improved in Canada over a number of years, despite a major policy focus on primary care, investments in payment reforms and the formation of groups and inter-professional teams.

Differences in performance trajectories could relate to the major structural differences in primary care between Canada and Israel. While Canada has universal health insurance coverage for necessary physician and hospital services, most physicians practice privately, are paid mainly through fee-for-service and have few accountabilities to the health care system. Many Canadians lack a regular source of primary care and there is little or no competition between primary care practices or groups, as most of them have full practices, and are not accepting new patients. No Canadian province has completely implemented electronic medical records in primary care. Canada also lacks the organizational, administrative and support structures of Israel's health maintenance organizations.

Canada and other countries can learn from the advances in data, measurement, feedback, and organization of care that are now applied routinely to ongoing quality improvement in Israel, with impressive results. The Israeli experience suggests that future developments designed to improve care and outcomes should include measurement infrastructure, formal reporting, accountability mechanisms, and management systems to address gaps and inequities in care.
\end{abstract}

\section{Commentary}

Rachel Podell and her colleagues at the National Program for Quality Indicators in Community Healthcare in Israel $(\mathrm{QICH})$ have provided a clear and engaging description of the quality of primary care provided to the elderly in Israel including changes over time, variation across sub-groups, and comparisons with other countries. Over a 13 year timeframe, most of the included process measures improved substantially with fairly minor differences between demographic groups and

Correspondence: rick.glazier@ices.on.ca

${ }^{1}$ Institute for Clinical Evaluative Sciences, Toronto, Canada

${ }^{2}$ Centre for Urban Health Solutions at St. Michael's Hospital, Toronto, Canada Full list of author information is available at the end of the article largely favourable comparisons with other countries. Other evidence from QICH indicates improvements in process measures for other age groups and conditions [1] and in enhanced equity and improved disease-specific outcomes including mortality [2]. Israel has one of the most advanced systems of monitoring the quality of primary care [3] and the OECD has noted the excellence of Israeli primary health care [4].

There are few direct comparisons of primary care available between Canada and Israel, but Canadian primary care compares relatively unfavourably with ten other developed countries in a number of measures including timely access to care, after-hours care, electronic medical record use and audit and feedback for quality 
improvement [5]. More concerning is that few of these measures have improved over a number of years despite a major policy focus on primary care [6] and investments in payment reforms and formation of groups and inter-professional teams [7]. While some areas such as cancer screening and diabetes care have improved [8], many aspects of primary care quality have been static over time and there are several examples of where reforms have not achieved their objectives $[9,10]$.

Differences in performance trajectories could relate to the major structural differences in primary care between Canada and Israel. While Canada has universal health insurance coverage for necessary physician and hospital services, most physicians practice privately, are paid mainly through fee-for-service and have few accountabilities to the health care system. Many Canadians lack a regular source of primary care [11] and there is little or no competition between primary care practices or groups as the majority are full and are not accepting new patients [12]. No Canadian province has completely implemented electronic medical records in primary care [5]. In contrast, Israel has the advantage of universal enrolment in one of four competing health maintenance organizations, employed physicians and other providers, full capture of electronic medical record encounters, prescriptions and tests and a robust quality reporting mechanism using population-based data.

It is unclear which of these mechanisms alone or in combination, and which additional factors have driven improvements in primary care processes and outcomes in Israel and it is therefore challenging to understand precisely what lessons Canada and other countries could learn from the Israeli example. Nonetheless, several key elements that are present in Israel and often missing in Canada are likely necessary for driving substantial improvements in population health outcomes. For example, many Canadian jurisdictions lack access to fundamental patient-level data such as prescribing, test results, blood pressure measurements, smoking status and body weights. In every jurisdiction a substantial proportion of the population lacks a primary care provider and in many jurisdictions those that have one are not registered or rostered with that provider, making attribution to a provider challenging. Electronic medical records are now used by most primary care physicians in Canada but many practices are unable to use their own data for quality improvement [5] and only a minority receive routine feedback on performance $[13,14]$. In the absence of attributable data and mechanisms for accountability there are limited opportunities to use quality measurement as a strategy to improve population health. Canada also lacks the organizational, administrative and support structures of Israel's health maintenance organizations [15].
Of course there are many contextual differences between countries that could drive differences in primary care quality and in changes over time. Canada has a vast land mass with $1 / 100$ th the population density as Israel, providing major challenges in care for remote communities. Canada has a higher proportion of seniors and higher net migration than Israel [16], both of which could increase need for care. Yet Canada spends 25\% more per GDP on health than Israel and has a higher proportion of health spending in the public sector [17], suggesting that it receives lower value for its spending.

There are reasons for optimism for Canadian primary care. While accessing care can be challenging, once patients see a primary care provider they report very good patient experience and preventive care ratings are the highest of eleven countries [18]. Routine data extraction from electronic medical records is occurring for disease surveillance, research and quality improvement [14] and has the potential to be scaled up to close to the population level. Canada's 14 health care jurisdictions mean that country-wide data and inter-jurisdictional comparisons are challenging but there is a commitment to build a National Data Platform to help surmount those barriers [19]. Group-based governance models are increasing in primary care, as is a move to alternate payment systems that could be accompanied by greater accountability and greater support for quality improvement.

\section{Conclusions}

The Podell at et al. article provides a clear and compelling description of data-driven improvements in the quality of primary care provided to the elderly in Israel. Canada and other countries can learn from the advances in data, measurement, feedback, and organization of care that are now applied routinely to ongoing quality improvement in Israel, with impressive results. In contrast, little improvement in outcomes has taken place in Canadian primary care despite substantial policy advances and investments. The Israeli experience suggests that future developments designed to improve care and outcomes should include measurement infrastructure, formal reporting, accountability mechanisms, and management systems to address gaps and inequities in care.

\section{Authors' contributions}

RG is the sole author. The author read and approved the final manuscript.

\section{Authors' information}

Richard Glazier is a Senior Scientist and Scientific Lead for Primary Care and Population Health at the Institute for Clinical Evaluative Sciences, a Family Physician and Scientist in the Centre for Urban Health Solutions at St. Michael's Hospital and a Professor of Family and Community Medicine at the University of Toronto. His undergraduate medical training was at the University of Western Ontario, his postgraduate Family Medicine training was at Queen's University, Ontario, Canada and his graduate training and residency in General Preventive Medicine and Public Health was at Johns Hopkins University in the U.S. 


\section{Commentary on}

Podell R, Kaufman Shriqui V, Wolff Sagy Y, Manor O, Ben-Yehuda A: The quality of primary care provided to the elderly in Israel. Isr J Health Policy Res. 2018, 7(1):21.

\section{Ethics approval and consent to participate} Not applicable.

\section{Consent for publication}

Not applicable.

\section{Competing interests}

Richard Glazier was an invited speaker at the 6th International Jerusalem Conference on Health Policy in 2016 and he has previously published with Vered Kaufman Shriqui. He has no other interests to declare.

\section{Publisher's Note}

Springer Nature remains neutral with regard to jurisdictional claims in published maps and institutional affiliations.

\section{Author details}

${ }^{1}$ Institute for Clinical Evaluative Sciences, Toronto, Canada. ${ }^{2}$ Centre for Urban Health Solutions at St. Michael's Hospital, Toronto, Canada. ${ }^{3}$ Family and Community Medicine at St, Michael's Hospital and University of Toronto, Toronto, Canada.

Received: 6 July 2018 Accepted: 29 July 2018

Published online: 03 August 2018

\section{References}

1. Manor O, Shmueli A, Ben-Yehuda A, Paltiel O, Calderon R, Jaffe DH. National Program for quality indicators in community healthcare in Israel report, 2008-2010. Jerusalem: School of Public Health and Community Medicine, Hebrew University-Hadassah; 2012.

2. Calderon-Margalit R, Cohen-Dadi M, Opas D, Jaffe DH, Levine J, Ben-Yehuda $A$, et al. Trends in the performance of quality indicators for diabetes care in the community and in diabetes-related health status: an Israeli ecological study. Isr J Health Policy Res. 2018;7:10.

3. Bramesfeld A, Wensing M, Bartels P, Bobzin H, Grenier C, Heugren M, et al. Mandatory national quality improvement systems using indicators: an initial assessment in Europe and Israel. Health Policy. 2016;120:1256-69.

4. OECD Reviews of Health Care Quality. Israel 2012. Raising Standards. https:// read.oecd-ilibrary.org/social-issues-migration-health/oecd-reviews-of-healthcare-quality-israel-2012_9789264029941-en\#page1. Accessed 31 July 2018

5. Canadian Institute for Health Information. How Canada compares: results from the Commonwealth Fund 2015 international health policy survey of primary care physicians. Ottawa: ClHI; 2016. https://www.cihi.ca/en/ commonwealth-fund-survey-2016. Accessed 31 July 2018.

6. 2003 First Ministers' Accord on Health Care Renewal. http://www.scics.gc.ca/ CMFiles/800039004_e1GTC-352011-6102.pdf. Accessed 31 July 2018.

7. Hutchison B, Levesque J-F, Strumpf E, Coyle N. Primary health care in Canada: systems in motion. Milb Quart. 2011:89(2):256-88.

8. Kiran T, Kopp A, Moineddin R, Glazier RH. Longitudinal evaluation of physician payment reform and team-based care for chronic disease management and prevention. CMAJ. 2015;187(17):E494-502.

9. Pineault $R$, Borgès Da Silva $R$, Provost $S$, Breton $M$, Tousignant $P$, Fournier $M$, et al. Impacts of Québec primary healthcare reforms on patients' experience of care, unmet needs, and use of services. Int J Fam Med. 2016;2016:Article ID 8938420.

10. Lavergne MR, Law MR, Peterson S, Garrison S, Hurley J, Cheng L, et al. A population-based analysis of incentive payments to primary care physicians for the care of patients with complex disease. CMAJ. 2016;188:E375-83.

11. Access to a Regular Medical Doctor. 2014. https://www150.statcan.gc.ca/n1/ pub/82-625-x/2017001/article/54863-eng.htm. Accessed 31 July 2018.

12. What Do We Know About Family Physicians Who Accept New Patients? https://secure.cihi.ca/free_products/aib_what_do_we_know_en.pdf. Accessed 31 July 2018

13. MyPractice: Primary Care. http://www.hqontario.ca/Quality-Improvement/ Guides-Tools-and-Practice-Reports/Primary-Care. Accessed 31 July 2018.

14. Canadian Primary Care Sentinel Surveillance Network. http://cpcssn.ca/. Accessed 31 July 2018.
15. Rosen B, Pawlson LG, Nissenholtz R, Benbassat J, Porath A, Chassin MR, et al. What the United States could learn from Israel about improving the quality of health care. Health Aff (Millwood). 2011;30(4):764-72.

16. Country profiles: regional facts and figures. http://www.oecd.org/regional/ regional-policy/country-profiles.htm. Accessed 31 July 2018.

17. Health at Glance 2017. OECD Indicators. https://read.oecd-ilibrary.org/socialissues-migration-health/health-at-a-glance-2017_health_glance-2017-en\#page1. Accessed 31 July 2018

18. Canadian Institute for Health Information. How Canada compares: results from the Commonwealth Fund's 2016 international health policy survey of adults in 11 countries. Ottawa: CIHI; 2017. https://www.cihi.ca/en/ commonwealth-fund-survey-2016. Accessed 31 July 2018.

19. Strategy for Patient-Oriented Research (SPOR) National Data Platform. https://research-tools.mun.ca/funding/opportunities/strategy-for-patientoriented-research-spor-national-data-platform-registration/. Accessed 31 July 2018 .

\section{Ready to submit your research? Choose BMC and benefit from:}

- fast, convenient online submission

- thorough peer review by experienced researchers in your field

- rapid publication on acceptance

- support for research data, including large and complex data types

- gold Open Access which fosters wider collaboration and increased citations

- maximum visibility for your research: over $100 \mathrm{M}$ website views per year

At BMC, research is always in progress.

Learn more biomedcentral.com/submissions 